\title{
La apropiación política-jurídica de la «vida» en el pensamiento biopolítico
}

\author{
Leonardo Sebastián Traverso \\ Estudiante de la Licenciatura en Filosofía \\ Universidad Nacional del Nordeste \\ traversoleo@gmail.com
}

\section{Resumen.}

Este trabajo fue realizado para la asignatura Seminario II (Análisis de un Problema Filosófico) y la realización del mismo implicó un grato esfuerzo. Partiendo desde una perspectiva comparativa entre los autores Foucault, Agamben y Esposito se visualiza que la política busca apropiarse de la «vida» sirviéndose del derecho como herramienta fundamental. Se analiza cómo estos autores llamados "biopoliticos", con sus respectivas particularidades, coinciden en que a través de dispositivos y tecnologías se interviene la vitalidad diseccionándola con el escalpelo político y en todos los casos el derecho actúa en auxilio de este proceder. El derecho, en los tres abordajes, es la herramienta por excelencia que la política utiliza para intervenir en la «vida» ya sea, amplificándola, destruyéndola, diluyéndola, ergo decidiendo sobre su naturaleza y alcance.

\section{Abstract.}

The present work was performed for the Course "Seminar II" (related to the analysis of a Philosophical Problem) and it implied a pleasant effort. Starting from a comparative perspective between Foucault, Agamben and Esposito, it is shown that politics pretends to appropriate "life" by using law as a fundamental tool. We will analyze how these authors, the so-called "biopolitics", with their respective peculiarities agree that vitality is intervened with dispositives and technologies, with the political scalpel and in all cases the law acts to assist this proceeding. The law, in their three approaches, is the tool par excellence that politics uses to interfere in "life", amplifying it, destroying it, diluting it, i.e. deciding on its nature and scope. 


\section{Introducción.}

Son múltiples las intervenciones que tanto la religión, la filosofía, las ciencias y el arte tienen sobre la «vida». Toda intervención se basa previamente en una forma de interpretar la «vida», es ingenuo pensar que una interpretación pueda definir lo vital, porque éste siempre excede a toda interpretación, siempre se escapará a toda pretensión de apropiación totalizante. Sin embargo, desde la antigüedad hasta nuestros días, se han montado y desmontado creencias, teorías, sistemas, dispositivos, tecnologías, mediante las cuales han segmentado aspectos de la vitalidad social e individual y con ello la imposición de normas y el ejercicio regular del poder. Este trabajo esquematiza el pensamiento biopolítico de Foucault, Agamben y Esposito; mostrando tres maneras, con sus diferencias y similitudes, mediante las cuales lo político procura apropiarse de la vida montando un sistema o dispositivo con el auxilio del derecho.

Los aportes que realiza Foucault al analizar el modelo de poder soberano y los modelos de poder anantomopolítico y biopolítico, representan mecanismos jurídicopolíticos en los cuales se verifican las intervenciones sobre lo vital.

Por su parte, Agamben continúa gran parte de los lineamientos que Foucault inauguró décadas atrás, pero fija su propuesta en un dispositivo fáctico-jurídico, al cual denomina "estado de excepción", cuya dinámica de exclusión inclusiva es una paradoja que amplia inmensamente su espacio, diluyendo todo límite, y se vuelve la ambigua herramienta que la política, desde el siglo XX y hasta nuestros días, utiliza por excelencia para hacer su interpretación de la «vida».

El aporte de Esposito es el planteo del "paradigma inmunitario", el cual, consiste en la intervención directa del derecho sobre lo vital. La técnica del derecho, como instrumento de poder que la política utiliza, no solo interpreta la vida en el sentido de que decide aquello digno de vivir o de morir, sino que, incluso, tal intervención deviene necesaria por serle complementaria a la comunidad. Sin el derecho el cuerpo social está destinado a la violencia más salvaje y a su consecuente autodestrucción. 
La apropiación "política-jurídica" de la «vida» es dinámica y actúa conjunta y complementariamente. Así, el ejercicio del poder "político" imparte una interpretación segmentaria de la «vida», dándose de este modo un corpus, el que se materializa en el establecimiento sistemático de mecanismos discursivos y de tecnologías que aseguran el ejercicio efectivo de ese poder, desde lo macro social hasta sus niveles capilares. Mientras que el "derecho" le garantiza mediante su lenguaje propio (la ley) el regular funcionamiento de estos dispositivos, además programa sanciones cuando el poder se viera directa o indirectamente atacado en su corpus político, e incluso prevé la desaplicación de sí mismo ante situaciones excepcionales. La ambigüedad de la exceptio abre un espacio infinito de penetración política sobre la vida y forma parte del perfeccionamiento y afinamiento de la herramienta jurídica a la hora de establecer su hermenéutica de lo vital. Incluso la política llegará a sostener que la «vida» en el cuerpo social es posible si (y solo sí) es inmunizada por el derecho ergo intervenida por su interpretación y delimitación de lo que debe vivir y lo que debe morir.

En este trabajo describiré los procesos mediante los cuales aparece la intervención política sobre la «vida» en las diferentes propuestas de los autores Michel Foucault, Giorgio Agamben y Roberto Esposito, e inferiré de esa relación la tarea que le cabe al derecho. Específicamente examinaré en cada una de las propuestas de los autores biopolíticos, los modos en que indefectiblemente a partir de una interpretación política de lo vital se establecen bordes o límites a ese [ahora] objeto que es la vida-política. Asimismo, mostraré que el derecho es la herramienta que legitima la interpretación que la política hace de la «vida» y también cómo el derecho garantiza el regular funcionamiento de los dispositivos que constituyen el corpus político.

El problema es que en el imaginario social hay una consideración del derecho que no coincide en nada con lo que éste se ocupa de hacer. El imaginario social entiende que simplemente el derecho es el conjunto de leyes, reglamentos y deberes sociales que se deben cumplir para que la vida en sociedad sea posible. Sin embargo, tal "lectura" del derecho es la capa discursiva más superflua y líquida que, en este 
trabajo, procuro desentrañar mostrando el conjunto de dispositivos que se orquestan bajo un enmarañado sistema político que define la «vida» utilizando al derecho.

De fondo veo que el problema deviene como algo genuino, o que aparenta ser genuino. Existe una visión sesgada de lo que el derecho hace en el cuerpo social. El direccionamiento discursivo, los aparatos de conformación de subjetividades, el disciplinamiento social, crean en el conjunto de individuos una lectura de la vida, y de sus vidas, los fines que deben perseguir y los anhelos que deben abrigar. La importancia de este trabajo es que esquematizando los núcleos teóricos de los biopoliticos y trasluce que el derecho es la herramienta que le permite a la política crear en el cuerpo social una ilusión de la vida.

De las dinámicas propuestas teóricas de los biopoliticos, hago enlaces donde muestro sus diferencias y similitudes, y utilizo el material resultante para construir el edificio teórico que confirmará mi hipótesis. En pocas palabras es una deconstrucción encaminada a demostrar los objetivos de este trabajo. La metodología específica utilizada fue primero la selección del material bibliográfico, el respetivo fichaje, la confección de definiciones conceptuales y metodológicas, revisión de los argumentos en que se basa la posición teórica.

\section{Capítulo 1 - Foucault y la apropiación político-jurídica de la vida.}

\section{La tecnología del poder soberano (tánatopolítica).}

Michel Foucault en su obra "La voluntad de saber" explica que la principal atribución del soberano radica en su facultad legal de dar muerte al súbdito. El poder es pensado durante esta época en términos absolutos, ya que el soberano puede terminar con la vida de cualquiera de sus súbditos. El terror que produce tal atribución legal es la que generó durante tanto tiempo plena obediencia y sumisión a quienes lo detentaban. Esta fue una de las primeras tecnologías jurídico-política implementada antiguamente en una forma de ejercicio del poder denominado "absoluto".

Foucault se ocupa de explicar que tal atribución tiene como antecedente la vieja patria potestas del derecho romano, institución jurídica que también le brindaba al padre de familia la facultad legal de "disponer" de la vida de su hijo, incluso de 
quitársela si por algún motivo quisiera hacerlo. Tal atribución legal trasladada a un marco mayor, el de la organización político y jurídico, fue el antecedente directo del derecho soberano de "disponer" en igual sentido de sus súbditos.

Este dispositivo de poder, que reviste el ropaje jurídico conocido como el "derecho soberano de hacer morir" tiene un fondo, y ese fondo es el de "dejar vivir". El mecanismo disuasivo (la fuente de poder) de esta tecnología funcionó porque permitió que la vida de los súbditos pueda desarrollarse mientras no salten los límites (no atentar de ninguna manera en contra de la voluntad del soberano obedeciéndolo en todo). Entonces la vida de los hombres en la polis era posible, durante el no-hacer del soberano (dejar vivir), mientras que el hacer del soberano era la orden de ejecución (hacer morir). Foucault (2007) afirma: "El soberano no ejerce su derecho sobre la vida sino poniendo en acción su derecho de matar, o reteniéndolo; no indica su poder sobre la vida sino en virtud de la muerte que puede exigir" (p. 164). Lo que me interesa recoger de esto hasta aquí es cómo la vida de los súbditos (hombres) era el aspecto negativo de una tecnología del terror que lograba extorsionar a los hombres quedándose con sus cosas o con su sangre. El acento en esta tecnología está puesto en una tanatopolítica más que en una biopolítica.

El mecanismo político-jurídico (denominado "derecho soberano") es la forma negativa de intervención sobre la vida de los súbditos, es decir, el súbdito entregaba parte de su riqueza al soberano por orden legal de este (impuestos-tributos), esa entrega pseudo-voluntaria le permitía al súbdito no ofender al soberano y así conservar su vida. Mirando este mecanismo más de cerca, la vida de ese súbdito que trabajaba en el mercado o en la tierra, que empleaba su fuerza de trabajo (energía vital) lo hacía para su propia subsistencia y la de los suyos pero una cuantía de la energía laboral, al transformarla en ganancia, se la debía al soberano. Por tanto, la tecnología jurídico-política opera mecánicamente de la siguiente manera: la amenaza de muerte genera sumisión, la que se transforma en la entrega pseudo-voluntaria de una parte los bienes que el súbdito produce. Dicho de otra manera, el precio de vivir a cambio de un porcentaje "impuesto" de vida (energía laboral=tributo) para el soberano. De este modo el derecho penal como amenaza de muerte y el derecho 
tributario como extorsión sobre la vida, operan al servicio de una forma de interpretación política sobre la «vida» que tuvo lugar durante este período histórico.

\section{La tecnología del biopoder (anatomopolítica y biopolítica).}

Explica Foucault que el poder soberano operó hasta la llegada del contractualismo, donde el planteo teórico en su aspecto filosófico, jurídico y político cambió radicalmente, poniendo coto al derecho absoluto del soberano de "disponer" de la vida de los súbditos. Durante los siglos XVII y XVIII el cambio teórico discursivo limitó el derecho del soberano y se proclamaron los denominados "derechos fundamentales del hombre" cuyo fundamento es que el origen del poder proviene de Dios quien se lo otorga al pueblo y este a su vez se lo entrega a un 'hombre o grupo de hombres' para que asegure la vida y los bienes de los ciudadanos-súbditos.

En realidad, este cambio en la base teórica del pensamiento jurídico tuvo lugar porque venían operando transformaciones materiales y la administración que el poder tenía respecto a la organización económico-social. La interpretación política de la «vida», inversamente enunciada ahora como: "hacer vivir y dejar morir", coloca su acento en la biopolitica y el derecho como herramienta del poder acompaña tal cambio tomando su corpus en la pluma de los contractualistas "limitando" los derechos absolutos desde lo discursivo. Sin embargo, tal limitación es aparente, porque en realidad el poder soberano extiende sus fronteras a casi todos los aspectos de la «vida» humana.

Dice Foucault (2007) al respecto que: “...el derecho de muerte tendió a desplazarse [...] en las exigencias de un poder que administra la vida..." (p 165). La palabra clave en esta frase es "administra", porque en este nuevo paradigma el dispositivo de poder opera en dos sintonías no excluyentes entre sí, sino involucradas una respecto de la otra: la anatomopolítica y la biopolítica, micro-administra y macroadministra la «vida» de los hombres.

La micro administración opera sobre los cuerpos de los ciudadanos, controlandolos y vigilándolos ya sea en los cuarteles, las fábricas, las escuelas, los hospitales, disciplinándolos e imponiéndoles "normas", es decir, "normalizando" 
conductas. Esto significa que el poder establece modos "correctos" (admitidos) e "incorrectos" (degenerados-prohibidos) de vivir (transitar) la vida (tiempo vital). Así afirma Foucault (2007) que desde el siglo XVII:

...el cuerpo como máquina: su educación, el aumento de sus aptitudes, el arrancamiento de sus fuerzas, el crecimiento paralelo de su utilidad y su docilidad, su integración en sistemas de control eficaces y económicos, todo ello quedó asegurado por procedimientos de poder característicos de las disciplinas: anatomopolítica del cuerpo humano. (p. 168)

La otra faz del "biopoder" encargada de la macro administración comenzó a desarrollarse durante el siglo XVIII. Esta tecnología está centrada en la población (cuerpo-especie) y busca asegurar la «vida» organizando y administrando el conjunto de individuos en el medio ambiente en el que tiene lugar la vida en sociedad. Las acciones políticas están impulsadas por la estadística: la demografía, la natalidad, la morbilidad, etc. Al respecto dice Foucault (2007) que:

en el cuerpo transido por la mecánica de lo viviente y que sirve de soporte a los procesos biológicos: la proliferación, los nacimientos y la mortalidad, el nivel de salud, la duración de la vida y la longevidad [...] una biopolítica de la población. (p. 168)

Foucault en sus conferencias dictadas en el Colegio de Francia tituladas Defender la sociedad explica que ambas tecnologías (anatomopolítica y biopolitica) que constituyen el llamado biopoder no se excluyen una a otra ni se suprimen porque operan sobre niveles o escalas distintas, tienen superficies de sustentación distintos. Afirma el francés en estas conferencias que:

...esta nueva técnica de poder no disciplinario se aplica a la vida de los hombres [...] la nueva tecnología introducida está destinada a la multiplicidad de los hombres, pero no en cuanto se resumen en cuerpos sino en la medida en que forma, al contrario una masa global, afectada por procesos de conjunto que son propios de la vida, como el nacimiento, la muerte, la producción, la enfermedad, etcétera. (Foucault, 2001, p. 220) 
Habiendo esquematizado el biopoder resulta apropiado marcar que el derecho garantiza el regular funcionamiento en los dos dispositivos del biopoder. Estos presuponen una interpretación de la «vida» y generan, con el auxilio del derecho, su corpus jurídico-político en donde desplegarse y aplicarse regular y continuamente. Antes dije que la palabra clave era 'administrar', porque el derecho que toma protagonismo es el derecho administrativo, la especificidad de este derecho es que otorga el marco de principios, reglas y procedimientos que atañen al poder de policía del Estado. Foucault en sus conferencias tituladas Seguridad, Territorio y Población durante las últimas clases desarrolla al detalle la función de la policía. Tal institución cuyo fin era el esplendor del Estado, el pleno desarrollo de los ciudadanos, el embellecimiento de la ciudad (Foucault, 2006, p. 359), y todo ello implicaba la intervención regulada sobre los individuos, su disciplina y control en el cumplimiento de la norma, pero también la intervención sobre el medio en que viven, es decir, la urbanización, la circulación, la salubridad, etc.

La «vida» en un amplio sentido, no solo de los individuos, sino de estos y sus actividades en los distintos lugares, es el objeto que la policía se dedica a regular, controlar, vigilar, ordenar, sistematizar, para mejorarlo y darle óptimas condiciones en su desarrollo, buscando brindar "bienestar social". Para poder lograr estos objetivos, la política se sirve del derecho como instrumento que le posibilita los medios o mecanismos. Comienza el proceso de regulación de las leyes, facultad propia del Poder Ejecutivo, que a través de instrumentos legales establece especificidades en las distintas áreas de su competencia, tal como regulación urbana, de salud pública, habilitaciones, infracciones a los incumplimientos, en términos generales se encarga de la planificación, distribución y circulación de bienes, individuos y residuos. El derecho penal, tributario, civil, continúan su funcionamiento pero circunscripto al área o aspecto de la vida que regulaban desde antes, mientras que el derecho administrativo y los ordenamientos municipales, provinciales y nacionales comienzan a regular todos los demás espacios en que la vida tiene lugar. Al respecto Foucault (2007) afirma que: “...la ley funciona siempre más como una norma, y que la 
institución judicial se integra cada vez más en un continuum de aparatos (médicos, administrativos, etc.) cuyas funciones son sobre todo reguladoras" (p. 174).

Tomo uno de los ejemplos que utiliza Foucault que nos ayude a ilustrar alguna particularidad que presentó el desarrollo del biopoder. En Inglaterra, durante los siglos XVIII cuando los pobres se integraron al medio urbano donde vivían los ricos, prestaron utilidad para un amplio espectro de servicios laborales (sistema postal, transporte, recolección de basura) sin constituir ninguna amenaza para la salud de los acaudalados. Sin embargo, durante el trascurso del siglo XIX con la epidemia de cólera proveniente de París, la situación se volvió delicada por el riesgo de contagio que implicaba para las clases acaudaladas el convivir en el mismo medio urbano que la clase proletaria y los indigentes. Es por ello que Inglaterra, estableció mediante la llamada "Ley de pobres" un cordón sanitario autoritario en la cual se implementó:

...una asistencia fiscalizada, de una intervención médica que constituyó un medio de ayudar a los más pobres a satisfacer las necesidades de salud que su pobreza les impedía alcanzar; al mismo tiempo esto permitió mantener un control mediante el cual las clases ricas, o sus representantes en el gobierno garantizaban la salud de las clases necesitadas y, por consiguiente, la protección de la población privilegiada. (Foucault, 1999, p. 382)

Es visible que la implementación de una anatomopolítica en el sometimiento obligatorio y controlado, fiscalizado y relevado. A su vez, directamente inscripto en una biopolítica que a través de un aparato burocrático y autoritario asegura la supervivencia de todos los individuos y en particular de las clases dominantes.

El carácter autoritario de la ley sanitaria es fundamental, porque revela que el derecho se emplea como herramienta que garantiza cierta interpretación que se tiene de la «vida». Para entenderlo mejor es necesario imaginar una situación a partir del caso tomado. Por ejemplo, un indigente que no quisiera someterse a la vacunación, ni tratamiento o control estatal alguno, e invocara el derecho a la libertad consagrado en el ordenamiento constitucional o legal que para aquel entonces ya era parte de los derechos fundamentales del hombre y el ciudadano. Es sumamente improbable que el aparato judicial hubiera respetado tal invocación jurídica; la respuesta judicial habría 
obligado al indigente a someterse al tratamiento "preventivamente" para el cuidado de su propia salud y vida. Sin embargo, tal resolución respondería indirectamente al modo en que la política (el aparato político -clases acaudaladas) estableció una cierta interpretación de lo vital y del modo en que este debe ser resguardado, controlado y asegurado. El derecho a través de la ley de pobres y el conjunto de decretos, reglamentos, y prácticas consuetudinarias son la fuente jurídica que la política emplea para alcanzar la interpretación que establece sobre lo vital.

\section{Capítulo 2 - Agamben y la apropiación político-jurídica de la vida.}

Agamben tiene una propuesta teórica en la cual continúa una línea del pensamiento biopolítico que Michel Foucault había comenzado algunos décadas antes. Las reflexiones de este filósofo también fueron inspiradas por los desarrollos de otros dos pensadores, Benjamin y Hannah Arendt.

Adelanto que se pierde precisión cuando se quiere simplificar la compleja relación que mantienen zoé y bios, toda división analítica es a los fines de compresión teórica y es claro que al diseccionar algo "viviente» este pierde su dinámica. Sin embargo, el escalpelo del análisis teórico no deja otra opción si se quiere comprender la complejidad del funcionamiento, antes se debe entender cada una de las partes.

A continuación procederé de la siguiente manera, en el primer subtítulo se hará una disección que exhiba cada parte, para luego, en el segundo subtitulo recomponerlas explicando la dinámica viviente del estado de excepción como fenómeno biopolítico. Lo interesante del caso es que, en el desarmado y rearmado teórico, es posible visualizar cómo el derecho, como herramienta del poder político, es el linde que poco a poco gana superficie y dimensión, entrometiéndose (por aplicación o desaplicación) en todos los aspectos de la «vida».

\section{El locus del poder soberano entre bios y zoé.}

Agamben en su obra Medios sin fin comienza explicando que los griegos no disponían del término "vida», palabra que en nuestro vocabulario confunde los dos sentidos que en un inicio se distinguían plenamente, el de bios y zoé. La inicial 
distinción resulta ser el punto neurálgico en la propuesta teórica de Agamben, porque para comprenderla es necesario que previamente se ponga en cuestionamiento el término mismo de "vida», y se comprenda que antiguamente, en el origen de la civilización el lenguaje zanjaba dos sentidos que hoy confundimos. Si previamente no se restablecen aquellas diferencias, no se logrará visualizar el espacio o sitio ("locus") en donde este pensador monta su edificio teórico, que adelanto, lo hace en medio de ambos términos.

Agamben (2001) explica que: "zoé expresaba el simple hecho de vivir común a todos los vivientes (...) y bios, que significaba la forma o manera de vivir propia de un individuo o de un grupo" (p. 13). El término zoé alude a un tipo de "vida natural» o "mera vida reproductiva», "nuda vida», "simplemente hechos», "forma de vida»; mientras que bios es la "vida que se desarrolla en el ámbito de la polis», es una "vida cualificada», "forma-de-vida», "posibilidad de vivir, siempre y sobre todo potencia" (Agamaben, 2001, p. 14).

Explicitando las diferencias a partir del locus, considero que zoé es el lugar de los hechos, de los acontecimientos, donde no es posible interpretación ni juzgamiento sino simple observación y admisión del devenir, mientras que en bios, el locus implica las interrelaciones individuales, la posibilidad de fragmentación del tiempo y del espacio (causalidad) a través de la interpretación, lingüisticidad del ser y consecuente juzgamiento de "conductas" voluntarias (reino de la "libertad").

La vitalidad del hombre comprende ambos locus, y la propuesta de este teórico los reúne distinguiéndolos y creando en medio de ellos el llamado "estado de excepción". Pero iré poco a poco, Agamben toma el ejemplo que Foucault había utilizado en "La voluntad de saber", el de la patria potestas del antiguo derecho romano, que era la institución jurídica en la cual se dota de sentido jurídico a la vida (vita) del hijo como objeto de "disposición" del jefe de familia, es decir, de matarlo si quisiera. En Foucault mostré que el antecedente jurídico que sirvió como parte del fundamento del derecho soberano de hacer morir y dejar vivir, que lo expliqué como la tecnología jurídica de la tanatopolítica. Mientras que Agamben (2001) afirma que: “...la vida aparece originariamente en el derecho romano tan sólo como la 
contrapartida de un poder que amenaza con la muerte" (p. 15), esto significa que el derecho en su origen no distinguía la vida del hombre por el mero hecho de ser hombre, sino que la asimilaba a cualquier otro producto-objeto, la vida del hijo era producto del hacer del padre y este disponía de ella como de cualquier otro objeto que este produjese. En otras palabras, el hijo estaba a merced de la voluntad del padre y el derecho no lo amparaba sino hasta que cumpliera la mayoría de edad o fuera emancipado (emancipatio); o también podría decirse que, hasta tanto el hijo no alcanzara su libertad jurídica su locus era el de la nuda vida o zoé respecto a su padre, donde el derecho solo lo cifraba como objeto o producto susceptible de generar la reparación a su dueño-pater en caso de que terceros lo dañasen.

En el imperium del soberano todo súbdito se encuentra a su merced y debe morir cuando este lo ordene, es igual que el hijo respecto a su pater a escala mayor. El "estado de naturaleza" hobbesiano es el locus de la «nuda vida» que habilita que todo hombre tome la vida o bienes de cualquier otro hombre, Agamben (2001) dice: "el derecho ilimitado de todos sobre todo" (p. 15). Cada hombre experimenta una continua amenaza de muerte viviendo en este locus, por lo tanto, cada uno de los hombres estiman que para escapar del peligro inminente que representa la «nuda vida», deviene lógico y necesario pactar entre hombres para entregarle el monopolio de la violencia al soberano. De este modo los pactantes se sustraen (en conjunto) del locus «nuda vida» y pasan a conformar un nuevo sitio "el pacto político", cuya legitimidad proviene de la apelación del peligro multilateral del estado de naturaleza hacia el peligro unilateral del soberano. Una racionalidad que considera conveniente la sumisión bajo amenaza segura y determinada, a un estado de amenaza indeterminado.

La garantía de ingresar en el locus político es la obtención de la seguridad jurídica que posibilita una vida social "tranquila" por la limitación de la vibrante amenaza entre hombres, a excepción del soberano, quien no pactó con nadie y quien se encuentra respecto a todos (y cada uno de los hombres) en estado de naturaleza. El pacto es de hombre con hombre y este los transforma en ciudadanos (cive), pero el 
soberano no pacta con ninguno y pasa a ser su único legislador, verdugo y garante del pacto.

Dice Agamben (2001) al respecto que:

El estado de excepción, sobre el que el soberano decide en cada ocasión, es precisamente aquel en que la nuda vida, que, en la situación normal aparece engarzada en las múltiples formas de vida social, vuelve a plantearse en calidad de fundamento último del poder político. (p. 15)

El "estado de excepción" es el núcleo teórico de Agamben, pero no es susceptible de ser comprendido sin antes haber establecido al menos sintéticamente los presupuestos teóricos sobre los que opera, debido a que el "estado de excepción" como paradoja que es, se "ubica" en el umbral de ambos locus, entre la «nuda vida» (hechos, zoé) y el «pacto social» (derecho, bios).

Afirma nuestro pensador que: "La vida, que es ob-ligada, implicada en la esfera del derecho, puede serlo, en última instancia, sólo a través de la presuposición de su exclusión inclusiva, sólo en una exceptio" (Agamben, 2006, p. 41-42). Para explicitar esta afirmación vinculándola con lo que hasta aquí se ha tratado; diré que, el originario "estado político» constituido a partir del ficticio "pacto social", consiste en la inclusión del conjunto de contratantes dentro del locus político (estado de derecho) recientemente creado, dentro del cual a partir de ese momento se establece la exclusión de toda situación de violencia (muerte o sustracción de bienes) entre contratantes. A través del pacto los hombres excluyen una parte de la facticidad amenazante del estado de naturaleza. El soberano no pacta con ninguno de los hombres, es el receptor incondicionado del imperium (pleno poder), generado a partir del acuerdo entre pactantes cuyo objeto contractual entrega el pleno ejercicio de la violencia y del dictado de normas al soberano.

La excepción es la fuente misma del derecho, porque la ley adquiere su corpus incluyendo en el orden jurídico, aquellas situaciones fácticas que no estaban previstas en él (y por eso las incluye), pero lo hace para excluirlas, es decir, "elevarlas" a la categoría típica (artículo legal-norma), la exhibe o establece como situación normada. 


\section{El estado de excepción en la biopolítica.}

No es posible pensar al poder solo con un enfoque jurídico-institucional sino que hay que pensarlo desde la interpretación que la política hace de la vida y el ulterior uso que hace del derecho para garantizar su ejercicio efectivo. El asunto aquí es lograr demostrar esta hipótesis exhibiendo claramente los mecanismos que hacen posible esta afirmación. Antes se ha visto que el montaje teórico-jurídico del modelo de la soberanía estaba fundado en la interpretación que la política hizo del modo más "conveniente" de conservar la vida ante el inminente estado de guerra de todos contra todos. Este modelo se basaba entonces en una tantopolítica cuyo fundamento jurídico ya fue lo suficientemente expuesto.

En la modernidad y especialmente después del régimen nazi, progresivamente la política interpretar toda arista posible de la «vida» y lo hizo no negativamente (hacer morir, dejar vivir) sino que sobre todo en sentido afirmativo (hacer vivir dejar morir). Fundamentalmente la biopolítica consistió en que el poder se potenciaba cuando extraía energía vital de los ciudadanos, por ello multiplica los esfuerzos por alcanzar el mayor bienestar de la población. También puedo decirlo de otra manera, durante los siglos XVIII y XIX la política incluye la zoé en la polis, es decir, cuando la política a través de los mecanismos de control y disciplinamiento de los cuerpos lo hace para extraer de estos su fuerza vital y colocarla al servicio de su poder, que como se vio lo establece como válido no porque necesariamente lo imponga sino porque lo normaliza. Pero lo importante aquí es que a la política le interesa el hombre como «zoé» es decir como «energía vital» productiva. Esto es desde la mirada de la anatomopolítica, pero es igual si pienso la biopolítica, y me sirvo del ejemplo de la ley de pobres que ya fue tratada, a la política le interesa la conservación de toda la población (ricos y pobres) y estableció autoritariamente regímenes de vacunación y control obligatorio, por distintos motivos de acuerdo a la clase social.

El modelo político de poder no suprime el modelo soberano, y particularmente en el caso del autor bajo análisis ambos modelos están íntimamente ligados. Dice al respecto Agamben (2006) que: "la producción de un cuerpo biopolítico es la aportación original del poder soberano" (p. 16). La figura jurídica que mejor representa 
la pareja categorial de zoé y bios es la figura jurídica del homo sacer, el hombre que como tal por ser del mismo género que los demás en principio pertenecería a la comunidad (inclusión) pero que por alguna razón es expulsado de esta (exclusión) por aniquilarle su ropaje jurídico quedando desnudo «nuda vida», por lo cual, cualquier hombre puede matarlo sin consecuencia alguna.

El ejemplo del homo sacer es la imagen perfecta que permite visualizar el núcleo de su propuesta agambeniana que si bien nace de las reflexiones de Foucault en este punto toma su propio cauce. Lo que se muestra en el ejemplo es ese umbral de indecibilidad entre bios y zoé que tiene un ambiguo cuerpo fáctico-jurídico. Esta ambigüedad es la que se ensancha con la política del siglo $X X$, con el dictado de leyes que regulan la desaplicación del derecho (estado de sitio) y que tristemente se materializaron en los campos de concentración. Dice Agamben (2006) que:

...el hecho de que, en paralelo al proceso en virtud del cual la excepción se convierte en regla, el espacio de la nuda vida que estaba situada originariamente al margen del orden jurídico, va coincidiendo de manera progresiva con el espacio político, de forma que exclusión e inclusión, externo e interno, bíos y zoé, derecho y hecho, entran en una zona de irreductible indiferenciación. (p. 19)

La política que en siglos anteriores había utilizado el derecho para garantizar la interpretación de la muerte y de la vida, durante el siglo XX se logró instrumentalizar trágicamente y por completo el estado de excepción. Derecho y hecho son desde entonces un objeto más que el poder político adquiere para interpretar (a su modo) lo «vital».

Tomo un fragmento de Agamben (2006) que habla por sí mismo:

El estado de excepción, en el que la nuda vida era, a la vez, excluida del orden jurídico y apresada en él, constituía en verdad, en su separación misma, el fundamento oculto sobre el que reposaba todo el sistema político.

Lo terrible de eso es que la política lo advirtió y hoy día apela constantemente a situaciones de peligro social para ensanchar el estado de excepción consolidando sus nuevas reinterpretaciones de la «vida». 


\section{Capítulo 3 - Esposito y la apropiación político-jurídica de la vida.}

Otro notable representante de la disciplina filosófica que teoriza a partir del enfoque biopolítico es Roberto Esposito. Su propuesta pone el acento en un aspecto biologicista de la biopolítca.

\section{Esquema de la Bíos.}

Esposito comienza su obra titulada Bíos relatando cinco casos donde se expone cómo la política define la "vida», exterminando algunas vidas para "salvar" otras. La política en cada momento de la historia interpela a lo vital y define de este lo que vale y lo que no, es decir, establece una hermenéutica en la cual aniquilar se justifica en salvar. La decisión de aquello que se debe sacrificar en pos de la propia «vida» estaría amparado en un sistema inmunitario que el autor sostiene. El caso de Rusia 2002, donde la muerte de 128 rehenes es el precio de salvar a casi mil personas. El "bombardeo humanitario" en Afganistán (2001), donde la matanza indeterminada se justifica echando comida a los sobrevivientes/damnificados. El caso de la venta de plasma representa una selección biológico-política en la que los pobres se enferman para salvar a los ricos dentro de un país que se dice comunista (China 2003); etc.

Esposito establece que la inmunización es el vínculo entre la política de la vida y el conjunto de las categorías políticas modernas; en otras palabras, la inmunización liga a la biopolítica con la modernidad, y esto ocurre, especialmente, después de la implementación del totalitarismo nazi. Esposito (2006) afirma que: "para que la vida sea inmediatamente traducible a política, o para que la política adquiera una caracterización intrínsecamente biológica - debe aguardarse hasta el viraje totalitario de la década de 1930, especialmente en su versión nazi” (p. 18).

El principal rasgo de la política del siglo XX fue su "indistinción" con la «vida». Cuando los nazis establecen una interpretación de la vida que debe conservarse y de la vida que debe aniquilarse sistemáticamente, lo que ocurre es que la política (a su manera) se "expande" al dominio la «vida». La biopolítica contemporánea es, en definitiva, la indistinción entre política y vida, “...donde la vida queda atrapada, presa 
de una política que tiende a sojuzgar [interpretar y definir] su potencia innovadora" (Esposito, 2006, p. 54).

De lo que trata el problema para Esposito (2006) es de "la modificación del bíos por obra de una política identificada con la técnica..." (p. 20), este problema está en sintonía con la hipótesis del trabajo. El objetivo del presente trabajo implica mostrar que el derecho como tecnología es una herramienta (y la principal) que la política utiliza para interpretar y definir en cada momento histórico lo «vital» y lo hace activa y reactivamente; lo hace, por un lado, conservando, y por el otro, creando y destruyendo, en una dialéctica que, de fondo, opera por "voluntad de poder». La intervención hermenéutica que la política hace de la vida, se perfecciona con el afinamiento de las tecnologías, al punto de volverlas indistinguibles.

\section{Política de la vida y sobre la vida.}

Espósito retoma gran parte de los desarrollos que Foucault había hecho, principalmente en sus conferencias dictadas en el Colegio de Francia durante los veranos de los años 1976, 1978 y 1979. Afirma que el poder biopolítico se diferencia del poder soberano, porque responden a modalidades de interpretación de la «vida» no excluyentes; en palabras del autor:

...en el régimen soberano, la vida no es sino el residuo, el resto, dejado ser, salvado del derecho de dar muerte, en tanto que en el régimen biopolítico la vida se instala en el centro de un escenario del cual la muerte constituye apenas el límite externo o el contorno necesario. (Esposito, 2006, p. 57)

Hasta aquí hay una primera diferencia entre el modelo soberano y biopolítico. En cuanto a este último Esposito se avoca a sintetizar la estructura que Foucault había presentado en el curso del '78, cuyo "código" presenta tres partes: 1) el poder pastoral, cuyo núcleo es la "confesión"; 2) las artes de gobierno, donde el poder sale de si para vincularse con la vida y asegura buscar asegurarla a través del "bienestar" de los gobernados; 3) la ciencia de la policía, propiamente la tecnología jurídiconormativa que el poder gubernamental aplica sobre la vida de los gobernados para potenciarla y maximizarla conforme los fines que predefinió. Como se vio más arriba el 
derecho administrativo era el corpus jurídico que la política instrumentalizó permitiéndole disciplinar y normalizar las subjetividades, para, un siglo después, ordenar y dirigir los "intereses" de la población, que, a partir de entonces, delimitó y gobernó.

Creo que lo que interesa a Esposito de Foucault es quedarse a reflexionar sobre el modo en que la política se expande sobre la «vida», o dicho de otra manera, cómo la política se centra en expandir y potenciar lo «vital». En este sentido las tecnologías que la política utilizó durante del siglo XVIII y XIX se perfeccionaron en el totalitarismo del siglo $\mathrm{XX}$, donde la política se termina de imponer sobre la vida. Se consolida esta imposición con el "...desarrollo del biopoder e incremento de la capacidad homicida..." (Esposito, 2006, p. 64), donde el genocidio es la expresión más cabal de que la política define e interpreta la vida hasta el extremo más cruel y que el derecho reafirma esa definición.

\section{Immunitas, el dispositivo de "salud" social.}

Ya había adelantado que para Esposito el mecanismo inmunitario es lo que enlaza la modernidad con la biopolítica. Lo que a continuación se desarrollará esquemáticamente son dos aspectos nucleares de su pensamiento; el primero versa sobre su visión de la sociedad como un organismo "vivo" al cual la inmunización le asegura su supervivencia. El segundo es la función de la fuerza como complemento bélico fundamental para el desempeño del derecho en su función inmunizadora.

Ambos desarrollos están vinculados con los dos sentidos que el adjetivo "inmune" (del latín immūnis) tiene según la RAE; el primero de sus sentidos alude a «exento de ciertos oficios, cargos, gravámenes o penas», este sentido coincide con la primera parte del desarrollo que versa sobre la relación complementaria entre munus/in-munis; y el segundo sentido del adjetivo es «no atacable por ciertas enfermedades», el cual es coincidente con la segunda parte que versa sobre la relación entre derecho y fuerza. 


\section{La comunidad como co-implicación de la «vida» y el derecho.}

Precisamente el autor establece que derecho es un dispositivo cuyo funcionamiento inmuniza la sociedad, es decir, "el derecho conserva la comunidad mediante su destitución" (Esposito, 2005, p. 37).

Para comprenderlo mejor deviene necesario comenzar diciendo que el término "comunidad" etimológicamente establece la co-implicación de dos términos latinos que son: "com" y "munus" ("munitas"). El primero es el prefijo latino cuya función es la unión o colaboración y se puede traducir como 'colegir' o 'juntar'. Mientras que el mūnus es un sustantivo que alude 'al cumplimento de un deber', o de una 'función', también se traduce como 'obligación' o 'cargo'. El resultado de la co-implicación es el de "comunidad" (com-munitas) cuyo acento está colocado en las obligaciones, es decir, en los deberes que un hombre tiene respecto a los demás para poder unirse a ellos. Visto desde la posición individual se refiere a lo que pesa sobre los individuos. En tal sentido, "nadie es sujeto directo de derechos" (Esposito, 2005, p. 37), sino más bien de obligaciones.

Explica Esposito (2005) que el munus "tiende a confundir los límites de lo que es propio de cada uno de ellos con lo que es de todos, y por tanto de nadie" (p. 36), lo que quiere decir es que el poder conectivo es tan fuerte, y a la vez tan perjudicial si no se le coloca un freno, porque si no se lo hace se termina destruyendo aquello que unió naturalmente. Socialmente sin un dispositivo que separe, parcele o delimite lo propio de lo de los demás la guerra es inminente. Es por ello, que el derecho "inmuniza" ("immunitas"), ya que el prefijo latino "im" significa no, es decir, no permite que el poder conectivo se autodestruya, para evitar “...esta contaminación insostenible reacciona el derecho: reconstituye los límites amenazados por el poder conectivos del munus" (Esposito, 2005, p. 36).

El papel del derecho en el sistema social es "salvaguardar una convivencia entre los hombres expuesta naturalmente al riesgo de un conflicto destructivo" (Esposito, 2005, p. 35). De esta manera, inicialmente el derecho establece un vínculo negativo con la «vida», el conjunto de hombres interrelacionados (estado de naturaleza) advierten un estado de amenaza o de inminente autodestrucción porque lo propio no 
tiene cabida sino que todo es de todos, por lo cual recurren a la implementación de un paradójico dispositivo jurídico, el cual, asegura el dominio, reconduciendo esa inicial vida social "común", tan común que era confusa, para volverla "propia", para demarcar límites, parcelar aquello que estaba unido y de esta manera el derecho "conserva la comunidad mediante su destitución" (Esposito, 2005, p. 37). Para expresarlo de modo explícito, el derecho como dispositivo inmunitario hace es constituir una sociedad parcelada, separada, delimitada, destituyendo a una sociedad concentrada, unida, apegada. El derecho hace una sociedad "menos común" y "más propia".

Esposito siguiendo los desarrollos de Simone Weil afirma que: "...la sociedad jurídicamente regulada es unificada por el principio de común separación: sólo es común la reivindicación de lo individual, así como la salvaguarda de lo que es privado constituye el objeto del derecho público" (Esposito, 2005, p. 41).

Hasta aquí ha quedado plasmada la función del derecho como dispositivo complementario de la naturaleza social al asegurar la «vida», posibilitando la supervivencia de los hombres en conjunto. Continuaré por lo que denomino el "aspecto bélico del funcionamiento", es decir, la relación entre derecho y fuerza.

\section{La fuerza y la inmunitaria violencia del derecho.}

El lenguaje médico esta liado con el lenguaje bélico, la palabra inmunizar nos refiere la "introducción" (o salto de "fronteras") de agentes "extraños"-"extranjeros""diferentes"-"no-propios" en el organismo (sitio común separado) a fin de lograr la producción de "anti-cuerpos"-“defensas" contra los "ataques" que estos agentes extraños acometen. El resultado que se pretende es desarrollar el "fortalecimiento" del organismo preparándolo para repeler próximas invasiones. (El significado según la RAE de fortalecimiento es: "cosa que hace fuerte un sitio o una población").

La lógica que opera por detrás de este sentido de inmunización es el supuesto bélico, es decir, la utilización y desarrollo de la fuerza como elemento destructivo y conservador al mismo tiempo. Al respecto Esposito (2005) afirma que: "el derecho consiste en esto: una violencia a la violencia por el control de la violencia" (p. 46), lo 
que clarifica que la fuerza puede ser elemento de ataque y destrucción, o puede acompañar al derecho y ser elemento de conservación. El autor presenta la dinámica de la fuerza y el derecho con el ejemplo de un circuito que a continuación cito:

1) al comienzo siempre es un hecho de violencia -jurídicamente infundado- el que funda el derecho, 2)este último, una vez instituido, tiende a excluir toda otra violencia por fuera de él; 3) pero dicha exclusión no puede ser realizada más que a través de una violencia ulterior, ya no instituye, sino conservadora del poder establecido. (Esposito, 2005, p. 46)

La violencia en sí misma no puede ser suprimida de la sociedad por ser propia de ella y de cada individuo, la compone celularmente. Esposito (2005) citando a R. Girard afirma que: "la violencia es al mismo tiempo el instrumento, el objeto y el sujeto universal de todos los deseos (...) el significante de lo deseable absoluto" (p. 56).

La violencia que ciertos agentes profieren al cuerpo social es inmunizada por medio de una 'tipología de violencia estatal-procedimental', que detiene la hemorragia que estos causaron y de esta manera evita la muerte social por desangramiento. Esta tipología de violencia es lo que Esposito denomina la "doble sangre" que no es otra cosa que la "violencia de la violencia" aquella que evita el desangramiento y posee el carácter de una cosa eminentemente comunicable. Por lo tanto, cuando la violencia es acompañada y dirigida por el derecho, se pone en marcha el aparato inmunitario que se "fortalece" inoculando dosis no letales de violencia. Al respecto dice Esposito (2005) que "La intervención médica consiste en inocular un poco de la enfermedad, exactamente como en los ritos que inyectaban un poco de violencia en el cuerpo social para ponerlo en condiciones de resistir a la violencia" (p. 58).

De forma general en el tratamiento del autor es claro que el derecho es una herramienta que la política implementa en su interpretación de lo vital, perfeccionando y ajustando en cada época este dispositivo. Lo que digo es que en la propuesta del autor es claro que la política interpreta la «vida» como un organismo al cual se le debe implementar procedimientos de inmunización para su fortalecimiento y así asegurar su supervivencia. Imitando lo que hice con Foucault y con Agamben, sería apropiado poner un ejemplo en el cual se pueda figurar la propuesta de este autor. 
El derecho es lo que provee sustancialmente de protección al organismo social a través de su carácter inmunitario. Ahora bien, la manera en que el dispositivo jurídico actúa es a través de un procedimiento estatal que racionaliza el uso de la fuerza a quien ha incumplido la norma, es decir, a quien "ataca" -"invade" al organismo social. Aquel o aquellos individuos que consuman un delito tienen previstos un cierto procedimiento ritual en el cual son captados, rodeados y juzgados por el aparto policial y judicial. Se los introduce en un complejo dispositivo de venganza que en su despliegue extingue el peligro generado por el ataque de estos individuos, es decir, corta la hemorragia que la fuerza de esos agentes produjo en el cuerpo social mediante el proceso penal. El mecanismo institucional a través del proceso ritual "cierra" o "sutura" la herida y establece con la sentencia judicial la venganza jurídica (violencia de la violencia).

\section{Conclusión.}

El derecho es la herramienta que la política utiliza para interpretar la «vida». Esta hipótesis se vió confirmada en cada parte tratada en este trabajo. He ajustado en los tres autores una clave de lectura común, una forma única para inteligir los abordajes sobre el proceder de la política en su intervención de lo vital y el resultado ha dejado claro que los biopolíticos, con sus diferencias específicas, sostienen que el derecho, ya sea de modo histórico, por vía de excepción u orgánicamente, interviene la vida diagramando sobre esta los fines que la política le dicta.

Así cuando trabaje a Foucault en el tratamiento que hace del derecho soberano he mostrado como el derecho penal y el derecho tributario operaban al servicio de la política absolutista. Mientras que bajo el modelo del biopoder el derecho administrativo es el que tomó protagonismo, inmiscuyéndose en las conductas sociales e individuales y regulando los modos en que se debe vivir.

En Agamben, el estado de excepción, es el origen mismo del derecho, y es el dispositivo que ensancha (al punto de desdibujar) todo límite posible del derecho. La figura arcaica del homo sacer es el antecedente jurídico que la política ha deformado para crear un espacio de indecibilidad en donde puede realizar su voluntad de poder 
sin que los ordinarios límites del derecho se lo impidan, por la sencilla razón de que antes articuló una ampliación del dispositivo jurídico donde este se sustrae de sí mismo (desaplicación) permitiendo que lo ilegal se transforme en meros hechos (zoé).

Esposito, va más allá que Foucault y Agamben, identifica en el paradigma inmunitario el complemento fundamental que la vida necesita para ser «vida». Lo que significa, que para que la vida sea "vida» es necesario que el derecho la intervenga (inmunizandola), por lo tanto, Esposito esta diciendo indirectamente que la política le dicta a la «vida» qué 'es', 'cómo es' y qué 'debe ser', en otras palabras, la política no solo interviene la vida sino que hasta la define, porque puede decidir que vive y que muere.

He mostrado y descripto los procesos mediante los cuales aparece la intervención política sobre la «vida» en las diferentes propuestas de los autores Michel Foucault, Giorgio Agamben y Roberto Esposito.

La política implementada y asegurada en el derecho soberano fue el mecanismo o tecnología que permitió apropiarse de la vida (energía de trabajo y bienes) de los súbditos a través del terror. Que tal mecanismo se agudiza y extiende cuando ajusta sus dispositivos para intervenir en cada individuo y disciplinarlo, registrarlo e implementar modos sistemáticos de direccionamiento de conductas. Asegurar y mejorar la vida de los individuos es para la política asegurar el poder sobre estos y el derecho jugó el papel central en el cumplimiento de ese objetivo.

He señalado que los bordes que el derecho tradicionalmente estableció, quedaron desdibujados cuando la política afinó su herramienta jurídica haciéndola a un lado bajo el nombre de "estado de sitio" para alcanzar los fines más espurios que se pudiesen imaginar en la aprehensión de la vida.

La inmunización como paradigma orgánico biológico del siglo XX y XXI que la política establece como fundamento para intervenir la vida bajo el discurso de componerla para su propia supervivencia es la forma más refinada. Los ejemplos de Rusia, China, Afganistán y muchos otros revelan los bordes monstruosos de la política y el grado de aprehensión en el que la «vida» es transformada. 


\section{Bibliografía:}

Foucault, M. (1999). Estrategias de poder. Obras esenciales, Volumen II. Barcelona. Paidós.

Foucault, M. (2007). La voluntad de saber. Historia de la sexualidad I. Madrid. Siglo XXI.

Foucault, M. (2001). Defender la sociedad. Buenos Aires. Fondo de cultura económica.

Foucault, M. (2006). Seguridad, Territorio y Población. Buenos Aires. Fondo de cultura económica.

Agamben, G. (2005). Estado de excepción. Homo sacer; II, I. Buenos Aires. Adriana Hidalgo.

Agamben, G. (2001). Medios sin fin Notas sobre política. Valencia. Pre-textos.

Agamben, G. (2006). Homo sacer. El poder soberano y la nuda vida I. Valencia. Pre-textos.

Esposito, R. (2006). Bíos. Biopolítica y filosofía. Buenos Aires. Amorrortu.

Esposito, R. (2005). Immunitas. Protección y negación de la vida. Buenos Aires. Amorrortu. 